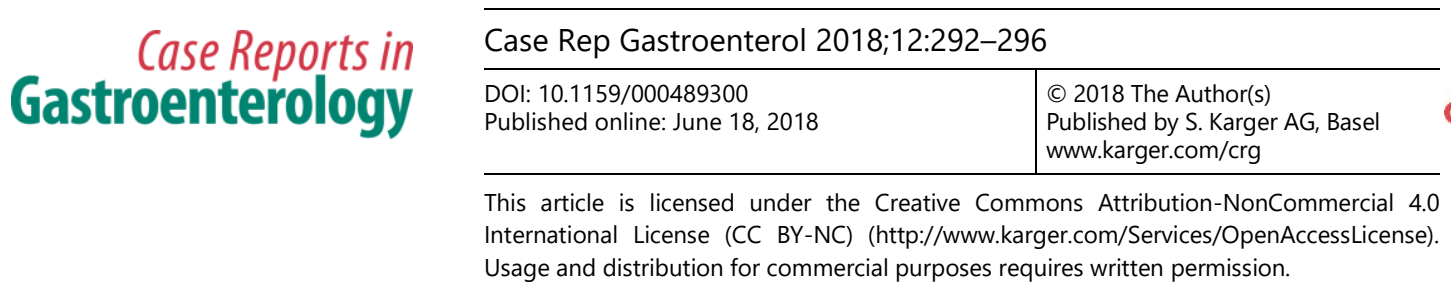

\title{
Unusual Cause of Gastrointestinal Bleeding in a Patient with Turner Syndrome
}

\author{
Rafael Bergesch D'Incao ${ }^{a} \quad$ Marcelo Campos Appel-da-Silva ${ }^{a}$ \\ Patricia dos Santos Marcon ${ }^{a} \quad$ Eduardo Marques Correa $^{\mathrm{a}} \quad$ Euler Manenti ${ }^{\mathrm{b}}$ \\ Carlos Otávio Corso ${ }^{c}$ \\ aDepartment of Gastroenterology and Endoscopy, Hospital Mãe de Deus, Porto \\ Alegre, Brazil; ' ${ }^{\text {b }}$ epartment of Cardiology, Hospital Mãe de Deus, Porto Alegre, Brazil; \\ 'Department of Surgery, Universidade Federal do Rio Grande do Sul and Hospital Mãe de \\ Deus, Porto Alegre, Brazil
}

\section{Keywords}

Turner syndrome · Gastrointestinal bleeding · Oral anticoagulants · Small bowel

\begin{abstract}
Turner syndrome is an exclusively female genetic disease caused by complete or partial absence of the second $X$ chromosome. It is classically characterized by congenital lymphedema, short stature, and gonadal dysgenesis. In addition, the syndrome is associated with several other abnormalities. One of them is gastrointestinal bleeding, which is frequently associated with inflammatory bowel disease, but it can also be caused by vascular lesions such as hemangioma, vascular ectasia, and telangiectasia. We report the case of a patient with Turner syndrome with an episode of gastrointestinal bleeding, outlining our pathway for the investigation and treatment of this condition.

(c) 2018 The Author(s) Published by S. Karger AG, Basel
\end{abstract}

\section{Introduction}

Turner syndrome is a chromosomal disorder that phenotypically affects females. It is characterized by complete or partial absence of the second X chromosome, associated with at least one clinical manifestation, such as typical facial features, webbed neck, lymphedema, 
growth failure, ovarian failure, sensorineural hearing loss, and cardiovascular, skeletal, digital, and renal abnormalities [1-3]. Gastrointestinal bleeding has been described in this population, especially in patients with inflammatory bowel disease [4, 5]. Additionally, episodes of gastrointestinal bleeding due to vascular malformations have been reported, although more rarely $[6,7]$. We report the case of a patient with a previous diagnosis of Turner syndrome who presented with significant gastrointestinal bleeding after the introduction of anticoagulant therapy and present a review of the related literature.

\section{Case Report}

A 22-year-old woman was admitted with gastrointestinal bleeding associated with enterorrhagia and melena. She had been diagnosed with Turner syndrome during childhood. Recently, she had undergone cardiac surgery due to heart valve malformation (mechanical heart valve replacement) performed approximately 2 months earlier, when full coumarin anticoagulation (sodium warfarin $5 \mathrm{mg}$ /day) was introduced. She had a history of two episodes of gastrointestinal bleeding during childhood, with spontaneous resolution and no etiology defined after investigation.

On admission, the patient was clinically stable, except for tachycardia (110 bpm) associated with severe anemia (hemoglobin $7.6 \mathrm{~g} / \mathrm{dL}$ ), requiring transfusion of 2 units of red bloodpacked cells. An upper gastrointestinal endoscopy was performed in the first $12 \mathrm{~h}$ of admission and showed no evidence of bleeding, but a colonoscopy performed 2 days later showed blood residues (melena) in all colonic segments and blood in the distal ileum, suggesting small bowel bleeding.

An abdominal CT angiography showed three active bleeding sites in the lower left quadrant, possibly in the distal jejunum and proximal ileum. Selective angiography was performed in an attempt to embolize the bleeding sites, but active bleeding could not be identified.

Due to the difficulty in locating the site of bleeding, the patient was referred to capsule endoscopy, which identified two active bleeding sites in the distal jejunum (Fig. 1). A doubleballoon enteroscopy revealed large, engorged vessels in the jejunoileal transition and an erosion covered with hematin with signs of recent bleeding. Therapeutic endoscopy was not indicated (Fig. 2).

Considering the endoscopic findings of prominent vascularization in the small bowel, the patient underwent a diagnostic laparoscopy, which allowed the identification of aberrant vascularization at the jejunoileal junction. An enterectomy with $60-\mathrm{cm}$ resection of the small bowel loops was performed (Fig. 3). Anatomopathological analysis showed medium-sized ectasic, congestive vessels in the mucosa and serosa compatible with vascular malformation.

The patient progressed well postoperatively, with no new episodes of bleeding. She has been on outpatient follow-up with no gastrointestinal bleeding relapse.

\section{Discussion}

Turner syndrome is an exclusively female genetic disease, with an estimated incidence of $1: 2,500$ to $1: 3,000$ female births [3]. It is classically characterized by congenital lymphedema, short stature, and gonadal dysgenesis [3]. In addition to these abnormalities originally described by Turner, the syndrome is also associated with coarctation of the aorta and skeletal abnormalities [8]. 
A relationship between gastrointestinal bleeding and Turner syndrome was first described by Lisser et al. [8], and the diagnosis was made by diagnostic laparotomy at the time. The presence of gastrointestinal bleeding in this group of patients should be initially considered a sign of inflammatory bowel disease, as previous studies have reported this association, with an estimated prevalence of 270:100 $000[4,5]$.

Vascular lesions of the gastrointestinal tract, such as hemangioma, vascular ectasia, and telangiectasia, are less frequently associated with gastrointestinal bleeding in this population [9-11]. These lesions are considered macroscopic representations of an underlying abnormality: ectasia of capillaries, venules, and veins [10]. Telangiectasia has an estimated prevalence of 7\% [8]. This lesion may occur at any part of the gastrointestinal tract, being more common in the small bowel, especially in the serosa, which makes the diagnosis difficult [4].

Vascular malformations usually cause intermittent episodes of lower gastrointestinal bleeding (melena), which tend to occur during the first 2 decades of life, with good response to iron replacement [6]. The frequency and severity of these episodes usually reduce with age $[7,11]$. However, in rare cases, bleeding may be severe, leading to hemodynamic instability and risk of death [7].

Investigation should begin with an upper gastrointestinal endoscopy, preferably within $24 \mathrm{~h}$, and, if lower gastrointestinal bleeding is suspected, a colonoscopy should be performed. Both methods are effective for investigation and treatment, but only if there are changes in the colon or duodenum $[10,11]$.

In the presence of visible bleeding not associated with hemodynamic instability, after an investigation of the upper and lower gastrointestinal tract, a capsule endoscopy should be performed as early as possible. This method has diagnostic accuracy of up to $67 \%$ in patients with visible bleeding and higher sensitivity and specificity than other techniques [12,13]. A double-balloon or push enteroscopy should be performed guided by a previous endoscopic capsule, which increases the diagnostic power and enables the use of therapeutic endoscopy $[12,14,15]$. Thus, due to advances in the methods of investigation of the small bowel, diagnostic laparoscopy has been used with restrictions, being reserved for the treatment of lesions that cannot be approached endoscopically.

Radiological examination is used in the following cases: (1) patients with evident bleeding, when capsule endoscopy is contraindicated (intestinal obstruction or abdominal surgery complications) or (2) in the presence of bleeding associated with hemodynamic instability [12]. Abdominal CT angiography or red blood cell scintigraphy are the methods of choice and, if an active bleeding site is identified, they can be complemented by an abdominal angiography enabling a therapeutic approach through embolization [14]. Barium enema and ultrasound show low diagnostic accuracy and have rarely been used in this type of investigation $[10,11]$.

Treatment of these abnormalities may include drugs, endoscopy, and surgery. Drug therapy is based on estrogen supplementation (associated or not with progesterone), due to greater microcirculatory stasis, in addition to a trophic effect on the mucosa and endothelial stabilization. It has shown benefits in the treatment of telangiectasias in the small bowel [16, 17]. However, drug therapy should be used only as adjuvant therapy, as there are few randomized trials and guidelines on its use [18]. Therapeutic endoscopy is effective when vascular lesions are within the reach of the endoscope, although the lesions are often multiple or not treatable [19]. Surgery is restricted to patients with active and refractory bleeding when therapeutic endoscopy and drug therapy are not feasible [6].

In the present case, we followed the latest guidelines for investigation of small bowel bleeding, which have also been used in recent reports of gastrointestinal bleeding related to 
D'Incao et al.: Unusual Cause of Gastrointestinal Bleeding in a Patient with Turner Syndrome

Turner syndrome [20, 21]. Our diagnostic approach was successful, with good outcome after surgery and resection of the examined segments.

\section{Statement of Ethics}

The authors have no ethical conflicts to disclose.

\section{Disclosure Statement}

The authors state that they have no conflicts of interest to disclose.

\section{References}

1 Gravholt CH, Backeljauw P, Conway GS, Dekkers OM, Geffner ME, Klein KO et al. New international Turner syndrome guideline: a multi-society feat. Eur J Endocrinol. 2017 Sep;177(3):E1-2.

2 Davenport ML. Approach to the patient with Turner syndrome. J Clin Endocrinol Metab. 2010 Apr;95(4):1487-95.

3 Sybert VP, McCauley E. Turner's syndrome. N Engl J Med. 2004 Sep;351(12):1227-38.

4 Price WH. A high incidence of chronic inflammatory bowel disease in patients with Turner's syndrome. J Med Genet. 1979 Aug;16(4):263-6.

5 Knudtzon J, Svane S. Turner's syndrome associated with chronic inflammatory bowel disease. A case report and review of the literature. Acta Med Scand. 1988;223(4):375-8.

6 Eroglu Y, Emerick KM, Chou PM, Reynolds M. Gastrointestinal bleeding in Turner's syndrome: a case report and literature review. J Pediatr Gastroenterol Nutr. 2002 Jul;35(1):84-7.

7 Frame B, Rao DS, Ohorodnik JM, Kwa DM. Gastrointestinal hemorrhage in Turner syndrome. Long-term follow-up with postmortem examination. Arch Intern Med. 1977 May;137(5):691-2.

8 Lisser H, Curtis LE, Escamilla RF, Goldberg MB. The syndrome of congenitally aplastic ovaries with sexual infantilism, high urinary gonadotropins, short stature and other congenital abnormalities; tabular presentation of 25 previously unpublished cases. J Clin Endocrinol Metab. 1947 Oct;7(10):665-87.

9 Redondo D, Swenson O. Gastrointestinal bleeding associated with gonadal aplasia. Surgery. 1967 Feb;61(2):285-7.

10 Burge DM, Middleton AW, Kamath R, Fasher BJ. Intestinal haemorrhage in Turner's syndrome. Arch Dis Child. 1981 Jul;56(7):557-8.

11 Reinhart WH, Mordasini C, Stäubli M, Scheurer U. Abnormalities of gut vessels in Turner's syndrome. Postgrad Med J. 1983 Feb;59(688):122-4.

12 Gurudu SR, Bruining DH, Acosta RD, Eloubeidi MA, Faulx AL, Khashab MA et al.; ASGE Standards of Practice Committee. The role of endoscopy in the management of suspected small-bowel bleeding. Gastrointest Endosc. 2017 Jan;85(1):22-31.

13 Katsinelos P, Lazaraki G, Gkagkalis A, Gatopoulou A, Patsavela S, Varitimiadis K et al. The role of capsule endoscopy in the evaluation and treatment of obscure-overt gastrointestinal bleeding during daily clinical practice: a prospective multicenter study. Scand J Gastroenterol. 2014 Jul;49(7):862-70.

14 Pennazio M, Spada C, Eliakim R, Keuchel M, May A, Mulder CJ et al. Small-bowel capsule endoscopy and device-assisted enteroscopy for diagnosis and treatment of small-bowel disorders: European Society of Gastrointestinal Endoscopy (ESGE) Clinical Guideline. Endoscopy. 2015 Apr;47(4):352-76.

15 Khashab MA, Pasha SF, Muthusamy VR, Acosta RD, Bruining DH, Chandrasekhara V et al.; ASGE Standards of Practice Committee. The role of deep enteroscopy in the management of small-bowel disorders. Gastrointest Endosc. 2015 Oct;82(4):600-7.

16 O’Hare JP, Hamilton M, Davies JD, Corrall RJ, Mountford R. Oestrogen deficiency and bleeding from large bowel telangiectasia in Turner's syndrome. J R Soc Med. 1986 Dec;79(12):746-7.

17 Cutsem E. Oestrogen-progesteron, a new therapy of bleeding gastrointestinal vascular malformations. Acta Gastroenterol Belg. 1993;56(1):2-10.

18 Szilagyi A, Ghali MP. Pharmacological therapy of vascular malformations of the gastrointestinal tract. Can J Gastroenterol. 2006 Mar;20(3):171-8.

19 Naveau S, Aubert A, Poynard T, Chaput JC. Long-term results of treatment of vascular malformations of the gastrointestinal tract by neodymium YAG laser photocoagulation. Dig Dis Sci. 1990 Jul;35(7):821-6. 
D'Incao et al:: Unusual Cause of Gastrointestinal Bleeding in a Patient with Turner Syndrome

20 Nudell J, Brady P. A case of GI hemorrhage in a patient with Turner's syndrome: diagnosis by capsule endoscopy. Gastrointest Endosc. 2006 Mar;63(3):514-6.

21 Qureshi MA, Mouzaki M, Le T. Diagnosis of small bowel telangiectasia in Turner's syndrome using capsule endoscopy. J Pediatr Endocrinol Metab. 2009 Aug;22(8):759-62. 